Metacognitions about desire thinking in binge eating

The final publication is available at Springer via http://dx.doi.org/10.1007/s40519-015-0205-0 


\title{
Metacognitions about desire thinking predict the severity of binge eating in a sample of Italian women
}

\author{
Regular Article \\ Word count (all sections included except tables): 5,143
}

Date of $5^{\text {th }}$ submission: 20/06/2015

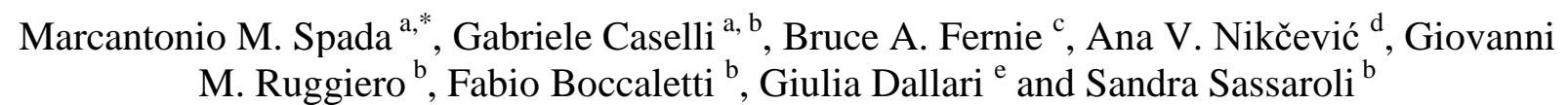

${ }^{a}$ Division of Psychology, School of Applied Sciences, London South Bank University, London, UK

${ }^{\mathrm{b}}$ Studi Cognitivi, Milan, Italy

${ }^{c}$ King's College London, Institute of Psychiatry, Department of Psychology, London, UK and CASCAID, South London \& Maudsley NHS Foundation Trust, London, UK

${ }^{\mathrm{d}}$ Department of Psychology, Kingston University, Kingston upon Thames, UK

${ }^{\mathrm{e}}$ University of Pavia, Pavia, Italy

* Correspondence to: Division of Psychology, School of Applied Sciences, London South Bank University, United Kingdom. Tel. +44 (0)20 7815 5760, e-mail spadam@1sbu.ac.uk.

\section{Acknowledgement}

Author BAF receives salary support from the National Institute for Health Research (NIHR) Mental Health Biomedical Research Centre and Dementia Research Unit at South London and Maudsley NHS Foundation Trust and King's College London. The views expressed are those of the authors and not necessarily those of the NHS, the NIHR or the Department of Health. 


\begin{abstract}
In this study our principal aim was to investigate whether metacognitions about desire thinking predict the severity of binge eating in women and, if so, whether this relationship is independent of age, self-reported Body Mass Index (BMI), negative affect, irrational food beliefs and craving. One hundred and four women, consisting of 32 consecutive patients with Binge Eating Disorder undergoing initial assessment for cognitive therapy for eating disorders, 39 moderate binge eaters, and 33 non-binge eaters (both from the general population), completed the following measures: Self-reported BMI, Hospital Anxiety and Depression Scale, Irrational Food Beliefs Scale, General Craving Scale, Metacognitions about Desire Thinking Questionnaire, and Binge Eating Scale. A series of Spearman's rho correlation analyses revealed that self-reported BMI, anxiety, depression, irrational food beliefs, craving, and all three factors of the metacognitions about desire thinking questionnaire were significantly associated with the severity of binge eating. A stepwise regression analysis identified self-reported BMI, craving, and negative metacognitions about desire thinking as significant predictors of the severity of binge eating. These results, taken together, highlight the possible role of metacognitions about desire thinking in predicting the severity of binge eating. The clinical implications of these findings are discussed.
\end{abstract}

Key words: binge eating; Binge Eating Disorder; craving; irrational food beliefs; metacognitions about desire thinking; negative affect, self-reported Body Mass Index. 


\section{Introduction}

\subsection{Binge Eating, Negative Affect and Irrational Food Beliefs}

Binge eating, which is defined as a discrete episode of overeating with loss of control (Striegel, Bedrosian, Wang \& Schwartz, 2012), is highly prevalent in the general population and particularly so in women (lifetime prevalence of approximately $1-5-2.0 \%$ for men and $3-3.5 \%$ for women; Kessler et al., 2013; Lavender et al., 2011; Luce, Crowther \& Pole, 2008). A variety of risk factors typically combine in predicting binge eating. For example, Andres and Saldana (2014), using structural equation modelling, have observed that body dissatisfaction is linked to dietary restraint which in turn is linked to binge eating. Research on similar lines has shown that body dissatisfaction predicts binge eating with dietary restraint and negative affect as mediators of this relationship (Holmes, Fuller-Tyszkiewicz, Skouteris \& Broadbent, 2015). Negative affect appears to be an important predictor of binge eating (e.g. Deaver, Miltenberger, Smyth, Meidinger \& Crosby, 2003; Meno, Hannum, Espelage \& Douglas, 2008; Saules et al., 2009; Spoor et al., 2006) with several theorists hypothesizing that binge eating functions as a coping strategy for reducing aversive states by providing temporary relief and distraction (Arnow, Kenardy \& Agras, 1992; Heatherton \& Baumeister, 1991; Polivy \& Herman, 1993; Wiser \& Telch, 1999). In support of this view, Leehr and colleagues' (2015) recent review on this subject area found evidence that negative affect serves as a trigger for binge eating in Binge Eating Disorder providing a short-term improvement of mood through food intake, irrespective of body weight.

It has also been postulated that irrational food beliefs may drive the activation of binge eating as a coping strategy for regulating negative affect (Osberg, Poland, Aguayo and MacDougall, 2008). These beliefs are characterised by distorted patterns of thinking which 
reflect unhealthy, unrealistic and extreme attitudes pertaining to food (e.g., "food is my only source of pleasure" and "food is a good way to lift depression"). Osberg and colleagues (2008) have found that the degree of endorsement of irrational food beliefs is a predictor of first semester weight gain, recent weight gain, and poor weight loss maintenance in university students. Irrational food beliefs have also been found to be correlated with bulimic symptoms in non-clinical samples (Osberg et al., 2008; Wang, Worsley \& Cunningham, 2009). More recently it has been suggested that the priming of irrational food beliefs may mediate binge eaters' tendencies to select high fat foods when under stress (Osberg \& Eggert, 2012).

\subsection{Desire Thinking and Metacognitions}

Desire thinking, a fast emerging construct in the arena of psychopathology, describes a voluntary thinking process characterized by the orientation to prefigure images, information, and memories about positive desired target-related experience (Caselli \& Spada, 2010; 2013; Kavanagh, Andrade \& May, 2005). Evidence indicates that desire thinking consists of two subcomponents: imaginal prefiguration and verbal perseveration (Caselli \& Spada, 2011). The imaginal prefiguration component refers to the allocation of attentional resources to targetrelated information and multi-sensory elaboration in the form of anticipatory positive imagery or positive target-related memories recall. The verbal perseveration component refers to prolonged self-talk regarding worthwhile reasons for engaging in target-related activities and their achievement. It has been argued (Caselli \& Spada, 2013) that desire thinking is a form of extended thinking which shares common features with worry and rumination (such as selffocused attentional orientation and perseveration) but is also distinct from these constructs because of its salient features of a greater degree of imagery-based elaboration, a more concrete 
focus on decision-making and planning instrumental behavior, and different emotional (e.g. craving vs. anxiety or depression) and behavioural (e.g. approach vs. avoidance) outcomes.

Though correlated to craving, desire thinking differs from this construct because it is a form of perseverative, conscious, and intentional target-related activity while craving describes an internal motivational experience (Caselli, Soliani \& Spada, 2013; Caselli \& Spada, 2010; 2011). Desire thinking has been found to predict various appetitive and addictive behaviours including alcohol, food, gambling, nicotine, and soft drinks controlling for craving and negative affect (e.g. Caselli, Ferla, Mezzaluna, Rovetto, Spada, 2012; Caselli, Nikčević, Fiore, Mezzaluna \& Spada, 2012; Caselli \& Spada, 2010; 2015; Fernie, Caselli, Giustina, Donato, Marcotriggiani \& Spada, 2014; May, Andrade, Panabokke \& Kavanagh, 2004; Spada, Caselli, Slaifer, Nikčević \& Sassaroli, 2014). Recent research has also suggested that desire thinking predicts the severity of binge eating controlling for self-reported BMI, negative affect and irrational food beliefs (Spada et al., 2015).

In their metacognitive model of addictive behaviors, Spada, Caselli and Wells (Spada, Caselli \& Wells, 2013; Spada, Caselli, Nikčević \& Wells, 2015) argue that metacognitions play a central role in understanding dysregulation in desire thinking. Metacognitions refer to knowledge or beliefs about one's own cognitive system and factors that affect its functioning and regulation (Wells, 1995). According to Wells (2000) metacognitions can be usefully divided into two broad sets: (1) positive metacognitions about control strategies that impact on inner events and (2) negative metacognitions concerning the significance, controllability and danger of inner events.

In the case of desire thinking, positive metacognitions about desire thinking concern the usefulness of desire thinking in controlling negative thoughts and emotion, in increasing positive sensations, in improving executive control over behaviour, and in planning how to reach goals. 
These metacognitions are thought to be involved in the initiation of desire thinking, in particular its imaginal prefiguration component. Examples of such positive metacognitions about desire thinking include: "Imagining something I desire helps me to feel better" and "Imagining what I desire helps me to have greater control over my choices". Negative metacognitions about desire thinking concern the uncontrollability of desire thinking, and its negative impact on executive control over behaviour, self-image, and cognitive performance. These metacognitions may play a role in propagating negative affect once a desire thinking episode begins, leading to its escalation (Caselli \& Spada, 2010; 2013; Spada, Caselli, Nikčević \& Wells, 2015) in the form of verbal perseveration. Examples of such negative metacognitions about desire thinking include: (1) "When I begin thinking about a desired activity/object I cannot stop" and "The images of what I desire persist not matter what I do to try to stop them" which concern negative metacognitions about the uncontrollability of the desire thinking process and its capacity to damage control over one's own behavior; and (2) "Thoughts about certain desires should be always avoided" and "Not being able to control my thoughts about what I desire is a sign of weakness" which concern metacognitions about the impact and need to control desire-related thoughts and includes.

Caselli \& Spada (2015) argue that the escalation of desire thinking to pathological levels, predominantly characterized by verbal perseveration (which prolongs conscious self-talk about reaching the desired target), is associated with the activation of negative metacognitions about desire thinking. The presence of such metacognitions should thus be a key marker of a maladaptive desire thinking process associated with the severity of binge eating.

\subsection{Aims of the Current Study}

To date no research has investigated the possible link between metacognitions about desire thinking and binge eating. Recent research would suggest that metacognitions about desire 
thinking should be associated to binge eating because levels of desire thinking have been linked to levels of binge eating, however we do not know which types of metacognitions about desire thinking may be relevant to the severity of binge eating. In addition, Binge Eating Disorder shares many similarities with other psychological problems where metacognitions are central (Wells, 2013). We thus hypothesised that metacognitions about desire thinking would be associated to the severity of binge eating and that this association would be independent of several key predictors of binge eating including self-reported BMI, negative affect, irrational food beliefs and craving. We proceeded firstly by examining the association between the predictor variables and the severity of binge eating and then by examining which of the predictor variables would best predict the severity of binge eating.

\section{Methods}

\subsection{Participants}

One hundred and four women (mean age=29.7; $\mathrm{SD}=9.5$; range 18-57) were recruited into this study from two sources: 32 consecutive patients (mean age=32.3; SD=10.3; range 18-51) diagnosed with Binge Eating Disorder (DSM-5; 2013) were recruited from a population which was undergoing initial assessment for cognitive therapy for eating disorders at the NOSCAE Hospital in Baggiovara, Modena, Italy, and at the Servizio Disturbi Alimentari dell'Azienda Ospedaliera C. Poma, Mantova, Italy; a further 72 participants were recruited through leaflets and advertisements in work environments and public places in Modena, Italy. According to the Binge Eating Scale (BES; Gormally, Black, Dasgon \& Rardin, 1982), of these 72, 39 (mean age $=25.5$; $\mathrm{SD}=9.6$; range 19-57) were classified as 'moderate binge-eaters' and 33 (mean age $=28.5 ; \mathrm{SD}=8.2$; range 20-54) were classified as 'non-binge eaters'. The BES classifies individuals as moderate or non-binge eaters using, respectively, score ranges of 18-26 and 17 or 
below. All participants who were diagnosed with Binge Eating Disorder were classified as 'severe binge-eaters' using the BES (i.e. a score of 27 or over). Table 1 presents the means for self-reported BMI, anxiety, depression, irrational food beliefs, craving, metacognitions about desire thinking, and binge eating scores.

\subsection{Procedure}

Ethics approval for the study was granted from the research institute where the second author works. The study was described to participants as an investigation of the role of emotion and thinking in eating behaviour. All participants were informed that data provided in the study would be treated with the strictest confidence and that participation in the research project was entirely voluntary. Following a brief introduction to the project and the granting of informed consent participants were instructed, both verbally and in written form, to complete the measures. All participants were debriefed following completion and scoring of the measures.

\subsection{Measures}

Self-reported Body Mass Index (SR-BMI). SR-BMI scores (weight in $\mathrm{Kg} / \mathrm{height}$ in $\mathrm{m}^{2}$ ) were calculated by asking the participants to provide their height in centimetres and weight in kilograms.

Hospital Anxiety and Depression Scale (HADS; Zigmond \& Snaith, 1983). The HADS consists of 14 items, seven assessing anxiety and seven assessing depression. Higher scores represent higher levels of anxiety and depression. Overall, the scale possesses good validity and reliability (Herrmann, 1997; Mykletun, Stordal \& Dahl, 2001; Zigmond \& Snaith, 1983). The scale has been validated in Italian (Costantini et al., 1999).

Irrational Food Beliefs Scale (IFBS; Osberg et al., 2008). The IFBS consists of 57 items, 41 of which are contained in the irrational food beliefs subscale, assessing cognitive distortions 
as well as inappropriate attitudes and beliefs about food. We administered only the irrational food beliefs subscale. Higher scores represent higher levels of irrational food beliefs. Overall, the scale possesses good validity and reliability (Osberg et al., 2008). The Italian version of the scale employed in the present study was back translated and shown to possess good internal consistency (Cronbach alpha=.83).

General Craving Scale (GCS; Flannery et al., 1999). The GCS is a modified version of the Penn Alcohol Craving Scale (PACS; Flannery et al., 1999). The PACS includes five items that measure the duration, frequency, and intensity of craving. Each question is scaled from 0 to 6. In the general version adopted in this study the five item structure was maintained but items were rephrased so as to refer to eating food. For Example item 1 of PACS "How often have you thought about drinking or how good a drink would make you feel?" was modified to: "How often have you thought about eating food or how good doing this would make you feel?" Higher scores represent higher levels of craving. The Italian version of the scale employed in the present study was back translated and shown to possess good internal consistency (Cronbach alpha=.80).

Metacognitions about Desire Thinking Questionnaire (MDTQ; Caselli \& Spada, 2013). The MDTQ consists of three factors. The first factor (eight items) concerns positive metacognitions about the usefulness of desire thinking as a strategy to enhance motivation and to distract from extended negative thinking and includes items such as: "Imagining something I desire helps me to feel better" and "Imagining what I desire helps me to have greater control over my choices". The second factor (six items) concerns negative metacognitions about the uncontrollability of the desire thinking process and its capacity to damage control over one's own behavior and includes items such as: "When I begin thinking about a desired activity/object I cannot stop" and "The images of what I desire persist not matter what I do to try to stop them". 
The third factor (four items) concerns metacognitions about the impact and need to control desire-related thoughts and includes items such as: "Thoughts about certain desires should be always avoided" and "Not being able to control my thoughts about what I desire is a sign of weakness". The MDTQ total score and factor scores have shown good factor structure, internal consistency, test-retest reliability, and both predictive and discriminative validity (Caselli \& Spada, 2013). This scale has been validated in Italian (Caselli \& Spada, 2013). For the purposes of the current study we asked participants to think about when they feel a desire to eat with a moderate or high intensity.

Binge Eating Scale (BES; Gormally, Black, Daston \& Rardin, 1982). The BES consists of 16 items assessing binge eating on the basis of behavioural characteristics (e.g., amount of food consumed) and the emotional and cognitive responses. Higher scores represent higher levels of binge eating. The scale has three scoring categories: 17 or below, 18-26, and 27 and higher. These respectively correspond to: non-bingeing, moderate bingeing, and severe bingeing. Overall, the scale possesses good validity and reliability (Gormally, Black, Daston \& Rardin, 1982) and has been widely used in both clinical and non-clinical research samples (Celio, Wilfley, Crow, Mitchell, \& Walsh, 2004). The scale has been validated in Italian (Di Bernardo et al., 1998).

\section{Results}

\subsection{Correlation Analyses}

A series of Kolmogorov-Smirnov tests revealed that the majority of study variables' distributions were significantly different than normal, except for anxiety, irrational food beliefs, and craving. As a result, a Spearman's rho correlation matrix was generated to explore the relationship between the predictor variables (including age) and the severity of binge eating 
(Table 1). These revealed that self-reported BMI, anxiety, depression, irrational food beliefs, craving, and all three factors of the metacognitions about desire thinking questionnaire were significantly associated with severity of binge eating. Table 1 also shows the means, standard deviations, and ranges for all study variables.

\subsection{Data Configuration and Stepwise Regression Analysis}

The data was tested against the assumptions of multiple linear regression analysis. No evidence of multicollinearity in the dataset was observed (no correlations greater than $\mathrm{r}=0.9$, no Tolerance Indexes below 0.10, and all Variance Inflation Factors of less than 10). Additionally, the Durbin-Watson test suggested that the assumption of independent errors was tenable. Histograms and normality plots indicated that residuals were normally distributed and plots of the regression-standardized residuals against the regression standardized predicted values suggested that the assumptions of linearity and homoscedasticity were met.

Variables that were significantly associated with the severity of binge eating were entered into a stepwise regression analysis with the severity of binge eating as the outcome variable. Following a four-step iteration self-reported BMI, craving, and both negative metacognitions about desire thinking factors were found to be significant predictors of the severity of binge eating. The final model accounted for $71.2 \%$ of the variance.

\section{Discussion}

Our findings demonstrated that, controlling for age, self-reported BMI, negative affect, irrational food beliefs and craving, negative metacognitions about desire thinking predicted the severity of binge eating. These findings align themselves with those observed across addictive and appetitive behaviours in highlighting the importance of metacognitions about desire thinking in predicting problem severity (for a review see Caselli \& Spada, 2015). 
Why would negative metacognitions about desire thinking be an independent predictor of the severity of binge eating? The likely explanation, in line with existing theoretical understanding and empirical findings, is that they drive the perseveration of desire thinking (Caselli \& Spada, 2015). In other words, the activation of these metacognitions signals that there is no possibility of actively controlling intrusions related to desire thinking (MDTQ-2) or discontinuing desire thinking (MDTQ-1). This is likely lead to the perseveration of desire thinking and the escalation of craving and negative affect, as the desired target (eating) is repeatedly elaborated upon but not achieved, leaving the option of eating as the primary route to obtain a degree of self-regulation (Caselli \& Spada, 2010; 2011; Spada, Caselli \& Wells, 2013; Spada, Caselli, Nikčević \& Wells, 2015). In support of this view, findings from correlated areas of psychopathology have repeatedly identified metacognitions about the uncontrollability of perseverative thinking processes (such as rumination and worry) as fundamental factors in predicting psychological distress and relapse following treatment (for a review see Wells, 2013). Our findings also align themselves with recent research showing links between general metacognitions and eating disorders (e.g. Cooper, Grocutt, Deepak \& Bailey, 2007; McDermott \& Rushford, 2011; Olstad, Solem, Hjemdal \& Hagen, 2015).

The results of this study have several potentially useful applications in the psychological treatment of binge eating. Current Cognitive Behaviour Therapy (CBT; e.g. Fairburn, Cooper \& Shafran, 2008) protocols may, for example, be potentiated by focusing on desire thinking and its key belief drivers (metacognitions). Evidence suggests that though CBT is an effective treatment, relapse rates remain moderately high (e.g. Brown \& Keel, 2012). Within the CBT model, focus on treatment remains rooted in challenging and modifying content-based beliefs (core beliefs, beliefs about self-worth, and irrational food beliefs) and extreme dietary restraint. Focusing on 
modifying metacognitions would address a higher order set of beliefs (metacognitions) involved in the control and regulation of cognition (Wells, 2013). In particular, tackling metacognitions about the uncontrollability of desire thinking may add a novel dimension to the understanding of the mechanics driving the escalation of craving/urges for food and consequently the initiation and frequency of binge eating.

If this were the case, assessment data could be gathered not only in relation to contentbased belief (such as irrational food beliefs) but also metacognitions related to the activation and perseveration of desire thinking. Interventions could also actively target the interruption of desire thinking and the modification of associated metacognitions. This could be achieved by shifting to a metacognitive mode of processing by gaining a flexible control over attention and thinking style and developing new plans of processing. Metacognitive Therapy techniques such as attention training technique (ATT), detached mindfulness, situational attentional refocusing (Wells, 2009) as well as visuospatial tasks (May, Andrade, Panabokke \& Kavanagh, 2010) may help to improve attentional and general cognitive flexibility, as well as provide disconfirmatory evidence of metacognitions: That is that desire thinking is subject to control and that metacognitions driving its perseveration are redundant.

This study has several limitations that need acknowledgement. First, it relies exclusively on self-report data which will inevitably be subject to errors in measurement (e.g. self-reported binge eating may be more reliant on the experience of a loss of control than having objectively consumed a large amount of food; Telch, Pratt \& Niego, 1998) and social desirability. Second, the cross-sectional nature of the design employed precludes causal inferences. Third, both dietary restraint and body dissatisfaction were not assessed as additional predictor variables and these have been associated with increased binge eating (e.g. Andres \& Saldana, 2014; Greeno, Wing \& 
Shiffman, 2000). Fourth, the presence of both Binge Eating Disorder and concurrent psychological disorder was not formally assessed in the non-clinical samples. Fifth, previous treatment may have exposed individuals to the identification and the exploration of cognitive constructs, nevertheless due to the novelty of the desire thinking construct it is unlikely that it will have been explicitly addressed as part of standard treatment for binge eating. Sixth, the study utilised a stepwise method to the regression analysis and therefore is vulnerable to the 'over-fitting' of models. Finally, desire thinking was not measured because the primary objective of the current study was to investigate the relative contribution of cognitive (irrational food beliefs) and metacognitive (metacognitions about desire thinking) belief domains to the severity of binge eating. However, measuring desire thinking would have allowed testing, for example, of whether the effects of belief domains (e.g. metacognitions about desire thinking or irrational food beliefs) on the severity of binge eating are mediated by desire thinking, potentially providing additional insights into the inter-relationships between these constructs and processes.

Directions for future research include investigating the role of metacognitions as longitudinal predictors of binge eating together with examining whether changes in metacognitions occur during treatment for binge eating. In conclusion, metacognitions about desire thinking appear to predict the severity of binge eating. If future research confirms this, then psychological interventions for treating binge eating may benefit from specifically targeting these belief domains.

On behalf of all authors, the corresponding author states that there is no conflict of interest. 


\section{References}

American Psychiatric Association (2013). Diagnostic and Statistical Manual of Mental Disorders (Fifth Edition).

Andres, A. \& Saldana, C. (2014) Body dissatisfaction and dietary restraint influence binge eating behavior. Nutrition Research, 34, 944-950. DOI:10.1016/j.nutres.2014.09.003; 32.

Arnow, B., Kenardy, J. \& Agras, W.S. (1992). Binge eating among the obese: A descriptive study. Journal of Behavioral Medicine, 15, 155-170. DOI: 10.1007/BF00848323.

Brown, T. A. \& Keel, P. K. (2012). Current and Emerging Directions in the Treatment of Eating Disorders. Substance Abuse, 6, 33-61. DOI: 10.4137/SART.S7864.

Caselli, G., Ferla, M., Mezzaluna, C., Rovetto, F. \& Spada, M. M. (2012). Desire thinking across the continuum of drinking behaviour. European Addiction Research, 18, 64-69. DOI: $10.1159 / 000333601$.

Caselli, G., Nikčević, A., Fiore, F., Mezzaluna, C. \& Spada, M. M. (2012). Desire thinking across the continuum of nicotine dependence, Addiction Research and Theory, 20, 382-88. DOI:10.3109/16066359.2011.644842.

Caselli, G., Soliani, M. \& Spada, M. M. (2013). The effect of desire thinking on craving: an experimental investigation. Psychology of Addictive Behaviours, 27, 301-6.

DOI:10.1037/a0027981.

Caselli, G. \& Spada, M. M. (2010). Metacognitions in desire thinking: a preliminary investigation. Behavioural and Cognitive Psychotherapy, 38, 629-637. DOI:10.1017/S1352465810000317. 
Caselli, G. \& Spada, M. M. (2011). The Desire Thinking Questionnaire: Development and psychometric properties. Addictive Behaviors, 36, 1061-1067.

DOI:10.1016/j.addbeh.2011.06.013.

Caselli, G. \& Spada, M. M. (2013). The Metacognitions about Desire Thinking Questionnaire: Development and psychometric properties. Journal of Clinical Psychology, 69, 1284-98.

DOI:10.1002/jclp.21999.

Caselli, G. \& Spada, M. M. (2015). Desire thinking: What is it and what drives it? Addictive Behaviors, 44, 71-79. DOI:10.1016/j.addbeh.2014.07.021.

Celio, A., Wilfley, D., Crow, S., Mitchell, J. \& Walsh, B. (2004). A Comparison of the Binge Eating Scale, Questionnaire for Eating and Weight Patterns-Revised, and Eating Disorder Examination Questionnaire with Instructions with the Eating Disorder Examination in the Assessment of Binge Eating Disorder and its Symptoms. International Journal of Eating Disorders, 36, 434-444. DOI: 10.1002/eat.20057.

Cooper, M. J., Grocutt, E., Deepak, K. \& Bailey, E. (2007). Metacognition in anorexia nervosa, dieting and non-dieting controls: A preliminary investigation. British Journal of Clinical Psychology, 46, 113-117. DOI: 10.1348/014466506X115245.

Costantini, M., Musso, M., Viterbori, P., Bonci, F., Del Mastro, L., Garrone, O., Venturini, M. \& Morasso, G. (1999). Detecting psychological distress in cancer patients: validity of the Italian version of the Hospital Anxiety and Depression Scale. Supportive Care in Cancer, 7, 121-127. DOI: $10.1007 / \mathrm{s} 005200050241$.

Deaver, C., Miltenberger, R., Smyth, J., Meidinger, A. \& Crosby, R. (2003). An evaluation of affect and binge eating. Behavior Modification, 27, 578-599.

DOI: $10.1177 / 0145445503255571$. 
Di Bernardo, M., Barciulli, E., Ricca, V., Mannucci, E., Moretti, S., Cabras, P. L. \& Rotella, C. M. (1998). Validazione della versione italiana della Binge Eating Scle in pazienti obesi. Minerva Psichiatrica, 39, 125-130.

Fairburn C. G., Cooper Z. \& Shafran R. (2008). Enhanced cognitive behavior therapy for eating disorders: The core protocol. In: Fairburn C. G. (Ed), Cognitive Behavior Therapy and Eating Disorders. Guilford Press: New York, USA. pp. 47-193.

Fernie, B.A., Caselli, G., Giustina, L., Donato, G., Marcotriggiani, A., \& Spada, M.M. (2014). Desire Thinking as a predictor of gambling. Addictive Behaviors, 39, 793-796. DOI: 10.1016/j.addbeh.2014.01.010.

Flannery, B. A., Volpicelli, J. R. \& Pettinati, H. M. (1999). Psychometric properties of the Penn Alcohol Craving Scale. Alcoholism: Clinical and Experimental Research, 23, 1289-1295. DOI: 10.1111/j.1530-0277.1999.tb04349.x.

Gormally, J., Black, S., Daston, S. \& Rardin, D. (1982). The assessment of binge eating severity among obese persons. Addictive Behaviors, 7, 47-55. DOI: 10.1016/0306-4603(82)90024-7.

Greeno, C. G., Wing, R. R. \& Shiffman, S. (2000). Binge antecedents in obese women with and with out binge eating disorder. Journal of Consulting and Clinical Psycohology, 68, 95-102. DOI: 10.1037/0022-006X.68.1.95.

Heatherton, T. F. \& Baumeister, R. F. (1991). Binge eating as escape from self-awareness. Psychological Bulletin, 110, 86-108. DOI: doi.org/10.1037/0033-2909.110.1.86.

Holmes, M., Fuller-Tyszkiewicz, M., Skouteris, H. \& Broadbent, J. (2015) Understanding the link between body image and binge eating: A model comparison approach. Eating and Weight Disorders, 20, 81-89. DOI: 10.1007/s40519-014-0141-4. 
Kavanagh, D.J., Andrade, J. \& May, J. (2005). Imaginary Relish and Exquisite Torture: The Elaborated Intrusion Theory of Desire. Psychological Review, 112, 446-467.

DOI: $10.1037 / 0033-295 X .112 .2 .446$.

Kessler, R.C., Berglund, P. A., Wai Tat Chiu, Deitz, A.C., Hudson, J. I., Shahly, V., AguilarGaxiola, S., Alonso, J., Angermeyer, M. C., Benjet, C. Bruffaerts, R., de Girolamo, G., de Graaf, R., Haro, J. M., Kovess-Masfety, V., O’Neill, S., Posada-Villa, J., Sasu, C., Scott, K., Viana, M. C. \& Xavier, M. (2013). The prevalence and correlates of binge eating disorder in the WHO World Mental Health Surveys. Biological Psychiatry, 73, 904-914. DOI: 10.1016/j.biopsych.2012.11.020.

Lavender, J. M., De Young, K. P. \& Anderson, D. A. (2011). Eating Disorders Examination Questionnaire (EDE-Q): Norms for undergraduate men. Eating Behaviors, 11, 119-121. DOI:10.1016/j.eatbeh.2009.09.005.

Leehr, E. J., Krohmer, K., Schag, K., Dresler, T., Zipfel, S. \& Giel, K. E. (2015). Emotion regulation model in binge eating disorder and obesity. A systematic review. Neuroscience Biobehavioral Review, 49, 125-134. DOI:10.1016/j.neubiorev.

Luce, K. H., Crowther, J. H. \& Pole, M. (2008). Eating Disorder Examination Questionnaire (EDE-Q): Norms for undergraduate women. International Journal of Eating Disorders, 41, 273-276. DOI: 10.1002/eat.20504.

May, J., Andrade, J., Panabokke, N. \& Kavanagh, D. (2004). Images of desire: cognitive models of craving. Memory, 12, 447-461. DOI: 10.1080/09658210444000061.

May, J., Andrade, J., Panabokke, N. \& Kavanagh, D. (2010). Visualspacial tasks suppress craving for cigarettes. Behaviour Research and Therapy, 48, 476-485.

DOI: 10.1016/j.brat.2010.02.001. 
McDermott, C. J. \& Rushford, N. (2011). Dysfunctional metacognitions in anorexia nervosa. Eating and Weight Disorders, 16, 49-55. DOI: 10.1007/BF03327521.

Meno, C., Hannum, J., Espelage, D. \& Douglas, L. (2008). Familial and individual variables as predictors of dieting concerns and binge eating in college females. Eating Behaviors, 9, 91101. DOI:10.1016/j.eatbeh.2007.06.002.

Mykletun, A., Stordal, E. \& Dahl, A. A. (2001). Hospital Anxiety and Depression Scale: factor structure, item analyses and internal consistency. British Journal of Psychiatry, 179, 540-544. DOI: 10.1192/bjp.179.6.540.

Olstad, S., Solem, S. Hjemdal, O. \& Hagen, R. (2015). Metacognition in eating disorders: Comparison of women with eating disorders, self-reported history of eating disorders or psychiatric problems, and health controls. Eating Behaviors, 16, 17-22. DOI: doi:10.1016/j.eatbeh.2014.10.019.

Osberg, T. M. \& Eggert, M. (2012). Direct and indirect effects of stress on bulimic symptoms and BMI: The mediating role of irrational food beliefs. Eating Behaviors, 13, 54-57. DOI:10.1016/j.eatbeh.2011.09.008.

Osberg, T. M., Poland, D., Aguayo, G. \& MacDougall, S. (2008). The Irrational Food Beliefs Scale: Development and validation. Eating Behaviors, 9, 25-40.

DOI:10.1016/j.eatbeh.2007.02.001.

Polivy, J. \& Herman, C. P. (1993). Etiology of Binge Eating: Psychological Mechanisms. In Christopher G. Fairburn and Terence G. Wilson (Editors), Binge Eating: Nature, Assessment and Treatment (pp. 173-205). New York, USA: Guilford Press. 
Saules, K., Collings, A., Hoodin, F., Angelella, N., Alschuler, K. \& Ivezaj, V. et al. (2009). The contributions of weight problem perception, BMI, gender, mood, and smoking status to binge eating among college students. Eating Behaviors, 10, 1-9.

DOI:10.1016/j.eatbeh.2008.07.010.

Spada, M. M., Caselli, G., Fernie, B. A., Manfredi, C., Boccaletti, F., Dallari, G., Gandini, F., Pinna, E., Ruggiero, G. M. \& Sassaroli, S. (2015). Desire thinking: A risk factor for binge eating? Eating Behaviors, 18, 48-53. DOI:10.1016/j.eatbeh.2015.03.013.

Spada, M. M., Caselli, G., Nikčević, A. V. \& Wells, A. (2015). Metacognition in addictive behaviors. Addictive Behaviors, 44, 9-15. DOI:10.1016/j.addbeh.2014.08.002.

Spada, M. M., Caselli, G., Slaifer, M., Nikčević, A. V. \& Sassaroli, S. (2014). Desire Thinking as a predictor of problematic Internet use. Social Science Computer Review, 32, 474-483.

DOI: $10.1177 / 0894439313511318$.

Spada, M. M., Caselli, G. \& Wells, A. (2013). A Triphasic Metacognitive Formulation of Problem Drinking. Clinical Psychology \& Psychotherapy, 20, 494-500.

DOI: $10.1002 /$ cpp.1791.

Spoor, S. T., Stice, E., Bekker, M. H., Van Strien, T., Croon, M. A. \& Van Heck, G. (2006). Relations between dietary restraint, depressive symptoms, and binge eating: A longitudinal study. International Journal of Eating Disorders, 39, 700-707. DOI: 10.1002/eat.20283.

Striegel, R. H., Bedrosian, R., Wang, C. \& Schwartz, S. (2012). Why men should be included in research on binge eating: Results from a comparison of psychosocial impairment in men and women. International Journal of Eating Disorders, 45, 233-240. DOI: 10.1002/eat.20962. 
Telch, C. F., Pratt, E. M. \& Niego, S. H. (1998). Obese women with binge eating disorders define the term binge. International Journal of Eating Disorders, 24, 313-317. DOI: 10.1002/(SICI)1098-108X(199811)24:3<313::AID-EAT9>3.0.CO;2-P.

Wang, W. C., Worsley, A. \& Cunningham, E. G. (2009). Social ideological influences on food consumption, physical activity, and BMI. Appetite, 53, 288-296. doi:10.1016/j.appet.2009.07.004.

Wells, A. (1995). Worry and the incubation of intrusive images following stress. Behaviour Research and Therapy, 33, 579-583. DOI:10.1016/0005-7967(94)00087-Z.

Wells, A. (2000). Emotional Disorders \& Metacognition: Innovative Cognitive Therapy. Chichester, UK: Wiley.

Wells, A. (2009). Metacognitive Therapy for Anxiety and Depression. New York, USA: Guilford Press.

Wells, A. (2013). Advances in Metacognitive Therapy. International Journal of Cognitive Therapy, 6, 186-201. DOI: 10.1521/ijct.2013.6.2.186.

Wiser, S. \& Telch, C. F. (1999). Dialectical behavior therapy for binge eating disorder. Journal of Clinical Psychology, 55, 755-768.

DOI: 10.1002/(SICI)1097-4679(199906)55:6<755::AID-JCLP8>3.0.CO;2-R.

Zigmond, A. S. \& Snaith, R. P. (1983). The Hospital Anxiety and Depression Scale. Acta Psychiatrica Scandinavica, 67, 361-370. DOI: 10.1111/j.1600-0447.1983.tb09716.x. 
Table 1: Means, standard deviations, ranges and correlation matrix of the study variables

\begin{tabular}{|c|c|c|c|c|c|c|c|c|c|c|c|c|c|}
\hline Measures & $\mathrm{X}$ & SD & Range & 1 & 2 & 3 & 4 & 5 & 6 & 7 & 8 & 9 & 10 \\
\hline 1. Age & 29.7 & 9.5 & $18-57$ & & $.36^{* *}$ & $-.27^{* * *}$ & -.04 & .08 & $-.23^{*}$ & .01 & .02 & -.05 & .02 \\
\hline 2. SR-BMI & 25.5 & 7.7 & $16-52$ & & & -.06 & .13 & $.30^{* *}$ & -.01 & $.20^{*}$ & $.27^{* *}$ & .06 & $.23^{*}$ \\
\hline 3. HADS-A & 9.4 & 4.6 & $1-21$ & & & & $.69^{* *}$ & $.32^{* *}$ & $.47^{* *}$ & $.27^{* *}$ & $.36^{* *}$ & $.39^{* *}$ & $.44^{* *}$ \\
\hline 4. HADS-D & 6.9 & 4.3 & $0-16$ & & & & & $.42^{* *}$ & $.50^{* *}$ & $.50^{* *}$ & $.50^{* *}$ & $.51^{* *}$ & $.59^{* *}$ \\
\hline 5. IFBS & 83.8 & 16.1 & $41-119$ & & & & & & $.27^{* *}$ & $.33^{* *}$ & $.37^{* *}$ & $.37^{* *}$ & $.45^{* *}$ \\
\hline 6. GCS & 19.9 & 6.8 & $5-35$ & & & & & & & $.46^{* *}$ & $.65^{* *}$ & $.47^{* *}$ & $.73^{* *}$ \\
\hline 7. MDTQ-1 & 10.7 & 3.4 & $8-27$ & & & & & & & & $.63^{* *}$ & $.46^{* *}$ & $.48^{* *}$ \\
\hline 8. MDTQ-2 & 12.5 & 5.5 & $6-24$ & & & & & & & & & $.65^{* *}$ & $.72^{* *}$ \\
\hline 9. MDTQ-3 & 10.1 & 3.9 & $4-22$ & & & & & & & & & & $.59^{* *}$ \\
\hline 10. BES & 20.5 & 11.6 & $0-42$ & & & & & & & & & & \\
\hline
\end{tabular}


Table 2: Stepwise multiple linear regression statistics with Binge Eating Scale scores as the outcome variable and selfreported BMI, negative affect, irrational food beliefs, craving and metacognitions about desire thinking as predictor variables

\begin{tabular}{|c|c|c|c|c|c|c|c|}
\hline \multirow[b]{2}{*}{ Predictor } & \multirow[b]{2}{*}{$R^{2}$} & \multirow[b]{2}{*}{ Adjusted $\mathrm{R}^{2}$} & \multirow[b]{2}{*}{ B } & \multirow[b]{2}{*}{ SE } & \multirow[b]{2}{*}{$\beta$} & \multicolumn{2}{|c|}{$\begin{array}{l}\text { 95\% Confidence } \\
\text { Interval }\end{array}$} \\
\hline & & & & & & LL & UL \\
\hline \multicolumn{8}{|l|}{ Step 1} \\
\hline MTDQ-2 & & & 1.63 & .13 & $.75^{* *}$ & 1.36 & 1.89 \\
\hline & $.56^{* *}$ & $.55^{* *}$ & & & & & \\
\hline \multicolumn{8}{|l|}{ Step 2} \\
\hline MTDQ-2 & & & .98 & .16 & $.45^{* *}$ & .66 & 1.30 \\
\hline GCS & & & .75 & .13 & $.44 * *$ & .50 & 1.00 \\
\hline & $.66 * *$ & $.65^{* *}$ & & & & & \\
\hline \multicolumn{8}{|l|}{ Step 3} \\
\hline MTDQ-2 & & & .74 & .16 & $.34 * *$ & .42 & 1.07 \\
\hline GCS & & & .88 & .12 & $.51 * *$ & .64 & 1.13 \\
\hline SR-BMI & & & .33 & .09 & $.21 * *$ & .16 & .51 \\
\hline & $.70 * *$ & $.69^{* *}$ & & & & & \\
\hline \multicolumn{8}{|l|}{ Step 4} \\
\hline MTDQ-2 & & & .53 & .18 & $.24 * *$ & .17 & .89 \\
\hline GCS & & & .88 & .12 & $.51 * *$ & .64 & 1.12 \\
\hline SR-BMI & & & .32 & .09 & $.20 * *$ & .15 & .49 \\
\hline MTDQ-3 & & & .49 & .19 & $.16^{*}$ & .11 & .87 \\
\hline & $.71 * *$ & $.70^{*}$ & & & & & \\
\hline
\end{tabular}

Note. SR-BMI = Self-reported Body Mass Index; GCS = General Craving Scale; MDTQ-2 = Metacognitions about Desire Thinking Questionnaire - Negative Metacognitions about Desire Thinking; MDTQ-3 = Metacognitions about Desire Thinking Questionnaire - Negative Metacognitions about the Need to Control Desire-Related Thoughts; LL = Lower Limit; UL = Upper Limit; $\mathrm{n}=104 ;{ }^{*} p<.05 ;{ }^{* *} p<.01$. 